\title{
Determinação da sensibilidade e da especificidade de um teste de ELISA indireto para o diagnóstico de linfadenite caseosa em caprinos
}

\author{
Renato Carminati* \\ Robson Bahia* \\ Lilia Ferreira de Moura Costa** \\ Bruno Jean Adrien Paule*** \\ Vera Lúcia Vale*** \\ Lia Regis**** \\ Songeli Menezes Freire***** \\ Ivana Nascimento****** \\ Robert Schaer******* \\ Roberto Meyer*******
}

\begin{abstract}
Resumo
Um teste de ELISA indireto foi desenvolvido e padronizado para o diagnóstico de linfadenite caseosa em caprinos. Foi usado como antígeno o secretado de cultura de $48 \mathrm{~h}$ de Corynebacterium pseudotuberculosis em caldo BHI. Para o estabelecimento do ponto de corte e cálculo da sensibilidade e da especificidade, foram usadas 31 amostras de soros de caprinos que apresentavam lesões características de linfadenite caseosa, das quais foi isolado C. pseudotuberculosis, e 56 amostras de soros de caprinos não infectados. A sensibilidade e a especificidade foram calculadas pela curva ROC. $\mathrm{O}$ teste de ELISA padronizado apresentou sensibilidade e especificidade de, respectivamente, 93,5\% e 100\%.
\end{abstract}

Palavras-chave: Linfadenite caseosa. Corynebacterium pseudotuberculosis. Caprinos. ELISA.

* Médico veterinário. Mestrando. Programa de Pós-Graduação de Imunologia. Instituto de Ciências da Saúde. UFBA. Laboratório de Imunologia e Biologia Molecular

Departamento de Biointeração

Instituto de Ciências da Saúde

Universidade Federal da Bahia

Av. Reitor Miguel Calmon s/n Vale do Canela

40.110-100 Salvador Bahia Brasil

E-mail: rcarminat@hotmail.com

** Professora de Microbiologia. Mestre em Imunologia. Instituto de Ciências da Saúde. UFBA.

*** Mestre. Doutorando. Programa de Pós-Graduação em Imunologia. Instituto de Ciências da Saúde. UFBA.

**** Mestre em Imunologia. Professora de Doenças das Aves. Escola de Medicina Veterinária. UFBA.

***** D. S. Imunologia. Vice-coordenadora do Programa de Pós-Graduação em Imunologia. Instituto de Ciências da Saúde. UFBA.

****** Professora de Imunologia. Doutoranda. Programa de Pós-Graduação em Imunologia. Instituto de Ciências da Saúde. UFBA.

******* Professor de Imunologia. Especialista em Imunologia. Instituto de Ciências da Saúde. UFBA.

******** Professor de Imunologia. Coordenador do Laboratório de Imunologia. Instituto de Ciências da Saúde. UFBA. 


\section{INTRODUÇÃO}

A linfadenite caseosa é uma doença infectocontagiosa crônica que acomete caprinos e ovinos. É caracterizada por um quadro de granulomas nos linfonodos, com material necrótico de cor esbranquiçada (AYERS, 1977). Os linfonodos comprometidos podem ser superficiais ou profundos e pode haver ainda lesões em vísceras. $\mathrm{O}$ agente etiológico da linfadenite caseosa é a bactéria Corynebacterium pseudotuberculosis (BENHAM; SEAMAN; WOODBINE, 1962; CAMERON; MINNAR; PURDON, 1969; BATEY, 1986).

No Nordeste do Brasil, existe uma alta prevalência de linfadenite caseosa nos rebanhos de caprinos (MOURA COSTA et al., 1973; UNANIAN; SILVA; PANT, 1985; BROWN; OLANDER; ALVES, 1987; RIBEIRO et al., 1988), o que resulta em graves prejuízos econômicos para esta região do país. Muitos dos pequenos criadores têm a caprinocultura como uma das suas principais atividades produtivas (RIBEIRO et al., 1988). De acordo com Alves e Olander (1999), a desvalorização da pele chega a $40 \%$, ocorre significativa diminuição na produção de leite, além de aumento de custeio pela exigência do uso de drogas e de mão-deobra destinadas ao tratamento dos granulomas superficiais.

O presente estudo foi conduzido para determinar a sensibilidade e a especificidade de um teste de ELISA indireto para o diagnóstico de linfadenite caseosa em caprinos, utilizando como antígeno a fração secretada em caldo BHI.

\section{MATERIAIS E MÉTODOS}

\section{Banco de soros}

Os trinta e um soros de caprinos infectados com C. pseudotuberculosis foram obtidos a partir do Banco de Soros Caprinos do Laboratório de Imunologia do Instituto de Ciências da Saúde da UFBA. Estes animais, sem raça definida, pertencentes a criadores do interior do Estado da Bahia, região de Santa Luz, apresentavam lesôes caseosas das quais foi isolado o agente etiológico.

Dos cinqüenta e seis soros negativos utilizados neste estudo, cinqüenta e quatro foram obtidos a partir de animais de raça pardo-alpina, provenientes do rebanho experimental da Escola de Medicina Veterinária e Zootecnia da USP, sem histórico de linfadenite caseosa, e dois soros foram obtidos do Banco de Soros Caprinos do Laboratório de Imunologia do Instituto de Ciências da Saúde da UFBA, tendo a mesma origem geográfica dos animais positivos para a doença, sendo, porém, provenientes de animais apresentando abscessos dos quais foi isolado Arcanobacterium pyogenes.

\section{Identificação do agente etiológico}

O material caseoso foi coletado no campo, usando-se técnica asséptica, e foi semeado em placas de ágar BHI enriquecido com $5 \%$ de sangue de carneiro. Após $48 \mathrm{~h}$ de incubação a $37^{\circ} \mathrm{C}$, em aerobiose, as colônias suspeitas de cada placa foram repicadas para outra placa de ágar BHI com 5\% de sangue de carneiro. Foi realizada coloração de Gram, e evidenciada a presença de bacilos gram-positivos curtos e pleomórficos. Foram realizadas provas de urease (meio de Christensen), catalase e fermentação de glicose. Em seguida, foi feita confirmação da identificação, usando-se galeria API Coryne (Bio Merieux, França). Foram realizadas, ainda, as provas da hemólise sinérgica com Rhodococcus equi ATCC33701 e inibição de $ß$ hemólise com Staphylococcus aureus ATCC 25923. Das trinta e três amostras de material caseoso coletado, C. pseudotuberculosis foi detectada em trinta e uma delas, e Arcanobacterium pyogenes, em duas.

\section{Protocolo do teste de ELISA indireto}

As placas de poliestireno de fundo chato (marca COSTAR) foram sensibilizadas com $50 \mu \mathrm{l}$ do sobrenadante da cultura de 48 h de $C$. pseudotuberculosis em caldo BHI, diluído a 1:100, em tampão carbonato bicarbonato a 0,05M, pH 9,6, incubadas a $4^{\circ} \mathrm{C}$ por 12 horas. Após duas 
lavagens com PBS contendo $0,1 \%$ de Tween20 , as placas foram bloqueadas com $200 \mu \mathrm{l} /$ poço de PBS-T20 contendo 5\% de leite desnatado, durante duas horas. A seguir, foram incubadas com $50 \mu \mathrm{l} /$ poço dos soros testes diluídos a 1:100 em PBS-T20 contendo 1\% de leite desnatado durante 1 hora. Após cinco lavagens em PBST20, adicionaram-se às placas $50 \mu \mathrm{l}$ de imunoglobulina de coelho anti-imunoglobulina de caprino, conjugada a peroxidase (DAKO), diluída a 1:10.000 em PBS-T20. As placas foram incubadas a $37^{\circ} \mathrm{C}$ por 45 minutos e, em segui$\mathrm{da}$, foram novamente lavadas cinco vezes em PBS-T20 e incubadas com $50 \mu \mathrm{l} /$ poço da solução reveladora $(25 \mathrm{ml}$ de tampão cítrico-fosfato $\mathrm{pH} 5,1+$ ortofenilenodiamina $10 \mathrm{mg}+10 \mathrm{ml}$ de $\mathrm{H}_{2} \mathrm{O}_{2}$ a $30 \%$ ). A placa foi incubada por 15 minutos à temperatura ambiente, ao abrigo da luz. A reação foi interrompida acrescentando-se $25 \mu \mathrm{lde} \mathrm{H}_{2} \mathrm{SO}_{4} 4 \mathrm{~N}$. A leitura foi feita em leitor de ELISA (Microplate Reader BIO-RAD Model 550), usando-se filtro de $490 \mathrm{~nm}$ de comprimento de luz.

\section{Cálculo do ponto de corte}

A definição do ponto de corte foi feita também através da curva ROC (receiver operator characteristic) ou curva operacional relativa (GREINER; SOHR; GOBEL, 1995; KABA; KUTSCHKE; GERLACH, 2001).

\section{Cálculo de sensibilidade, especificidade, valores preditivos negativo e positivo}

Os cálculos da sensibilidade e da especificidade foram feitos usando-se os resultados do ELISA obtidos a partir dos 87 soros testados, tendo como padrão-ouro o isolamento de $C$. pseudotuberculosis na lesão caseosa. Os valores preditivos positivo e negativo foram calculados com o valor de ponto de corte definido pela curva ROC.

\section{Análise estatística}

Os testes estatísticos apresentados foram feitos pelo programa SPSS versão 9.0.

\section{RESULTADOS}

\section{Ensaio imunoenzimático indireto com antígeno obtido em caldo BHI}

Os valores das leituras de DO para o teste de ELISA padronizado variaram de 0,072 a 0,250 , para os animais não infectados, e de 0,14 a 1,17 , para os soros de animais comprovadamente infectados.

\section{Definição do ponto de corte}

A curva ROC usada para determinação do ponto de corte do teste está representada na Figura 1. Esta curva apresenta a sensibilidade em função da proporção de falsos positivos (1 especificidade). Os valores dos pontos destacados representam os pontos de corte utilizados para o cálculo da sensibilidade e da especificidade. $\mathrm{O}$ ponto de corte definido em $\mathrm{DO}=$ 0,25 , localizado no canto superior esquerdo da curva ROC, é considerado como a melhor otimização possível dos valores de sensibilidade e especificidade do teste de ELISA. Para o ponto de corte definido em 0,25 unidade DO, a sensibilidade e a especificidade do teste foram de $93,5 \%$ e $100 \%$, respectivamente.

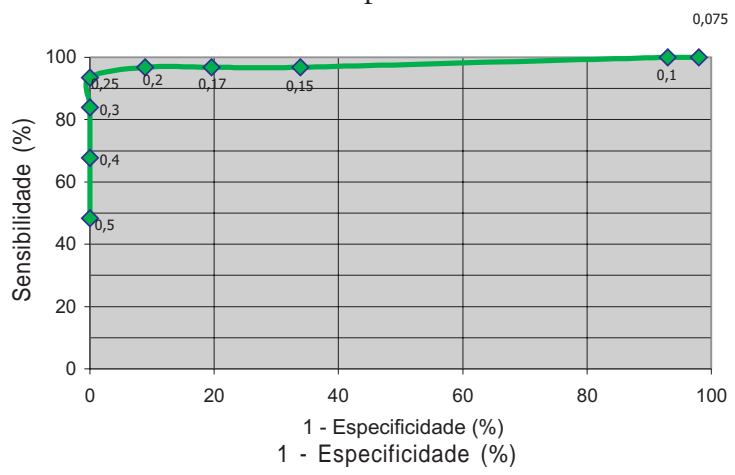

FIGURA 1 - Curva ROC expressando os resultados de sensibilidade e (1-especificidade) em função do ponto de corte escolhido do ELISA 
O Quadro 1 mostra como foram calculadas a sensibilidade e a especificidade para o teste de ELISA padronizado, para o ponto de corte definido como a DO de 0,25.

A Figura 2 apresenta a variação dos valores preditivos positivo e negativo em função da prevalência.

\begin{tabular}{lccc}
\hline & Com linfadenite & Sem linfadenite & TOTAL \\
\hline ELISA + & 29 & 0 & 29 \\
ELISA - & 02 & 56 & 58 \\
TOTAL & 31 & 56 & 87 \\
\hline
\end{tabular}

QUADRO 1 - Resultados do ELISA considerando ponto de corte $\mathrm{DO}=0,25$

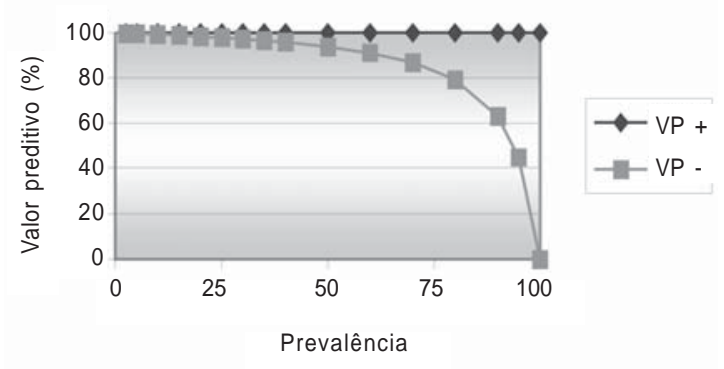

FIGURA 2 - Valor preditivo positivo e negativo do ELISA em função da prevalência

\section{DISCUSSÃO}

A sensibilidade e a especificidade são parâmetros fundamentais para a definição de um teste diagnóstico. Assim, quanto maior a sensibilidade do teste, maior a capacidade de o teste negativo afastar a doença, pois ocorre uma diminuição da probabilidade de falso negativo. Quanto maior a especificidade de um teste, maior a capacidade de o teste positivo indicar a doença, pois diminui a probabilidade de falso positivo (GREINER; GARDNER, 2000). Um aumento da sensibilidade decorre de uma diminuição da especificidade e vice-versa. Por esta razão, a determinação do ponto de corte ou cut off é importante. Um ponto de corte muito alto pode implicar em $100 \%$ de especificidade, uma vez que todos os testes positivos implicarão na existência da doença. No entanto alguns indivíduos com a doença podem obter resultados negativos, o que implica em baixa sensibilidade.

A análise ROC pode ser usada tanto para examinar o desempenho de um teste diagnóstico quanto aos possíveis valores de corte, como para comparar diferentes testes diagnósticos, a fim de escolher o melhor. De acordo com o gráfico descrito pela curva ROC, quanto maior a área definida pela curva, melhor será o teste. No teste de ELISA padronizado, para o ponto de corte definido, a sensibilidade foi de 93,5\%. Estes resultados se mostram acima dos obtidos por Kaba, Kutschke e Gerlach (2001), que trabalharam com o extrato da bactéria como antígeno. A sensibilidade obtida neste teste de ELISA foi muito próxima à descrita por Dercksen et al. (2000), que foi de $94 \pm 3 \%$ em um teste de ELISA tipo "sanduíche" indireto. Sting, Steng e Spengler (1998) propuseram um teste de ELISA indireto usando como antígeno o sobrenadante da cultura em caldo BHI. Estes autores obtiveram uma sensibilidade de $73 \%$ e uma especificidade de $92 \%$ em caprinos.

Com relação à especificidade, o resultado foi de $100 \%$ para o ELISA padronizado, resultado próximo aos obtidos por Kaba, Kutschke e Gerlach (2001), que foi de 96\%, e Dercksen et al. (2000), que foi de $98 \pm 1 \%$ para caprinos.

O ponto de corte foi definido de forma a melhorar a especificidade em detrimento da sensibilidade, uma vez que, em função da alta prevalência da linfadenite caseosa em nossa região, é mais interessante que haja uma maior probabilidade de o teste de ELISA ser negativo em animais sem a doença. A curva ROC foi importante na definição do ponto de corte por permitir uma visualização das variações de sensibilidade e especificidade em função do ponto de corte. Se, para determinação do ponto de corte para um número de controles negativos (n) igual a 30, fosse usada a média das DO somada a duas vezes o desvio padrão para um intervalo de confiança de 97,5\% (FREY; DI CANZIO; ZURAKOWSKI, 1998), teríamos 
um ponto de corte de 0,2 para o teste de ELISA desenvolvido, o que levaria a uma redução da especificidade para 91,1\%.

Os valores preditivos são influenciados pela prevalência da doença na população. Quanto maior a prevalência da doença, maior será o valor preditivo positivo e menor o valor preditivo negativo. Esta, entretanto, não influencia a sensibilidade e a especificidade do teste (DERCKSEN et al., 2000). O valor preditivo positivo do ELISA proposto foi calculado, para o ponto de corte definido, em $100 \%$, qualquer que fosse a prevalência da doença. $O$ valor preditivo negativo, por sua vez, alcançou $96,5 \%$ para a população observada. O presente estudo permite afirmar que, para uma faixa de prevalência entre $0 \%$ e $60 \%$, o valor preditivo negativo irá variar entre $100 \%$ e $91,1 \%$, respectivamente.

\section{CONCLUSÕES}

Os resultados do presente estudo permitem concluir que:

1) A sensibilidade e a especificidade do teste de ELISA desenvolvido com a fração secretada de C. pseudotuberculosis para diagnóstico da linfadenite caseosa em caprinos foram de $93,5 \%$ e $100 \%$ respectivamente.

2) O fato de se dispor de uma população de animais comprovadamente doentes (através do isolamento do agente etiológico) permitiu a utilização da curva ROC para a determinação do ponto de corte, otimizando, desta maneira, a sensibilidade e a especificidade do teste.

3) Os valores preditivos negativo e positivo do teste estarão acima de $90 \%$, qualquer que seja a prevalência da doença.

\title{
Sensitivity and specificity of an indirect ELISA test for diagnosis of caseous lymphadenitis in goats
}

\begin{abstract}
An indirect ELISA test was developed and standardized for the diagnosis of caseous lymphadenitis in goats. The culture supernatant of a $48 \mathrm{~h}$ culture of Corynebacterium pseudotuberculosis cultivated in BHI broth was used as antigen. In order to determine the cut off and the evaluation of the sensibility and the specificity, thirty one serum samples from infected goats with caseous lesions, whose presence of $\mathrm{C}$. pseudotuberculosis was confirmed by positive culture, were used, as well as fifty six serum samples from no infected goats. The sensitivity and the specificity of the test were calculated by ROC analysis. The sensitivity and the specificity of the ELISA BHI test were $93.5 \%$ and $100 \%$, respectively.
\end{abstract}

Keywords: Caseous lymphadenitis. Corynebacterium pseudotuberculosis. Goats. ELISA.

\section{REFERÊNCIAS}

ALVES, F. S. F.; OLANDER, H. Uso de vacina toxóide no controle da linfadenite caseosa em caprinos. Veterinária Notícias, n.5, p.69-75, 1999.

AYERS, J. L. Caseous lymphadenitis in goat and sheep: review of diagnosis, pathogenesis, and immunity. JAVMA, n.171, p.1251-1254, 1977.

BATEY, R. G. Pathogenesis of caseous lymphadenitis in sheep and goats. Aust. Vet. J., n.63, p.269-272, 1986.
BENHAM, C. L.; SEAMAN, A.; WOODBINE, M. Corynebacterium pseudotuberculosis and its role in diseases of animals. Commonwealth Bureau of Animal Health, v.32 p.645-657, 1962.

BROWN, C. C.; OLANDER, H. J.; ALVES, S. F. Synergistic hemolysis-inhibition titers associated with caseous lymphadenitis in a slaughterhouse survey of goats and sheep in Northeastern Brazil. Can. J. Vet. Res., n.51, p.46-49, 1987.

CAMERON, C. M.; MINNAR, J. L.; PURDON, M. R. Immunizing properties of Corynebacterium pseu- 
dotuberculosis cell walls. Onderstepoort J. Vet. Res., v.36, n.2, p.211-216, 1969.

DERCKSEN, D. P. et al. A comparison of four serological tests for the diagnosis of caseous lymphadenitis in sheep and goats. Vet. Microbiol., n.75, p.167-175, 2000.

FREY, A.; DI CANZIO, J.; ZURAKOWSKI, D. A statistically defined endpoint titer determination method for immunoassays. J. Immunological Methods, n.221, p.35-41, 1998.

GREINER, M.; GARDNER, I. A. Epidemiologic issues in the validation of veterinary diagnostic tests. Prev. Vet. Med., n.45, p.3-22, 2000.

GREINER, M.; SOHR, D.; GOBEL, P. A modified ROC analysis for the selection of cut-off values and the definition of intermediate results of serodiagnostic tests. J. Immunological Methods, n.185, p.123-132, 1995.

KABA, J.; KUTSCHKE, L.; GERLACH, G-F. Development of an ELISA for the diagnosis of
Corynebacterium pseudotuberculosis infections in goats. Vet. Microbiol., n.78, p.155-163, 2001.

MOURA COSTA, M. D. et al. Linfadenite caseosa dos caprinos no Estado da Bahia. Distribuição geográfica da doença. Boletim do Instituto Biológico da Bahia, v.12, n.1, p.1-7, 1973.

RIBEIRO, O. C. et al. Avaliação de vacina contra linfadenite caseosa em caprinos mantidos em regime extensivo. Pesq. Vet. Bras., n.8, p.27-29, 1988.

STING, R.; STENG, G.; SPENGLER, D. Serological studies on Corynebacterium pseudotuberculosis infections in goats using enzyme-linked immunosorbent assay. J. Vet. Med., n.45, p.209-216, 1998.

UNANIAN, M. M.; SILVA, F. A. E. D.; PANT, K. P. Abscesses and caseous lymphadenitis in goats in tropical semi-arid Northeast Brazil. Trop. Amm. Hlth. Prod., n.17, p. 57-62, 1985. 